\title{
Editorial
}

\section{Bone marrow transplantation and the lung}

Bone marrow transplantation is a remarkably easy technical procedure with enormous therapeutic potential, which is as yet only partially tapped because of a paucity of suitable donors and a high complication rate. Nevertheless the procedure offers the hope of curing the many and diverse clinical disorders that result from malfunction of the progeny of haemopoietic pleuripotential stem cells. The technique is capable of restoring normal haematological function in primary red cell, white cell, or platelet disorders after ablation of aberrant cells and can be used to rescue patients with marrow failure secondary to chemical or radiation insult. Immunological competence can be restored as grafted haematological stem cells are able to differentiate into $T$ and $B$ lymphocytes. Possibly many immunological disorders will be treated with bone marrow transplantation in the forseeable future. Bone marrow transplantation is also being studied as a form of treatment for metabolic disorders, including mucopolysaccharidoses, Gaucher's disease, and adenosine deaminase deficiency. ${ }^{1}$ By means of a graft of normal stem cells into an affected patient erythrocytes, granulocytes, and macrophages are produced and normal enzymes are manufactured, which then diffuse into enzyme deficient tissues. In 1986 two major difficulties, graft versus host disease and pulmonary damage, limit the widespread exploitation of bone marrow transplantation. $^{2-4}$

Graft versus host disease is thought to result because donor $\mathrm{T}$ lymphocytes recognise the recipient's tissues as foreign and, by mounting an immune response, damage them. In the first 100 days acute graft versus host disease presents as a rash, often accompanied by evidence of damage to the gut and liver, in $25-75 \%$ of patients. ${ }^{56}$ Later, chronic graft versus host disease may present by mimicking multiorgan autoimmune disease with rash, oral and ophthalmic sicca syndrome, hepatic damage, immune deficiency, and opportunistic infections. ${ }^{78}$ This may follow acute graft versus host disease or may occur de novo. For the accurate diagnosis of graft versus host disease biopsy and histological examination of the affected organ is required. Despite increasing understanding of histocompatibility determinants and recent advances in manipulating $T$ cell function, in most centres bone marrow transplantation is confined

Address for reprint requests: Dr ADJ Pearson, Department of Child Health, Medical School, Newcastle upon Tyne NE2 4HH. to patients who have sibling donors who are HLAAB-Dr identical and whose lymphocytes are nonreactive in mixed lymphocyte culture. But even when it becomes commonplace to transplant from unrelated histocompatible donors lung damage will continue to complicate and prejudice the clinical course of the patient with a bone marrow transplant.

The lung complications described in patients with bone marrow transplant are very diverse (table). The greatest threat after transplantation is interstitial pneumonitis, which in both American and European series has complicated recovery in up to one third of all patients treated and has had a mortality rate of nearly $75 \% .^{9-15}$ In over a half of all these patients active cytomegalovirus infection has been present. ${ }^{9-10}$

Bone marrow transplantation is at present generally performed for patients with aplastic anaemia and haematological malignancies, acute lymphoblastic leukaemia, acute myeloid leukaemia, and chronic granulocytic leukaemia. Where appropriate these conditions are treated by allotransplant. Marrow is harvested from a histocompatible sibling and transfused into the patient, who is preferably aged less than 45 years since the incidence of graft versus host disease increases substantially with age. The best results in acute lymphoblastic and acute myeloid leukaemia are obtained when the patient is in haematological remission with no overt disease in bone marrow or

\section{Early complications (within 100 days of bone marrow transplantation)}

1 Pulmonary oedema

(a) Fluid overload

(b) Myocardial damage

(c) Acute haemorrhagic-cyclosporin toxicity

2 Adult respiratory distress syndrome
(a) Septicaemia
(b) Idiopathic

3 Bronchopneumonia

(a) Bacterial

(b) Fungal

4 Interstitial pneumonitis

(a) Idiopathic (perhaps due to effect of cytotoxic drugs and irradiation)

(b) Infective-cytomegalovirus, pneumocystis, etc

5 Pulmonary embolism

Late complications (after 100 days from bone marrow transplantation)

1 Bronchopneumonia

2 Interstitial pneumonitis

3 Restrictive lung disease

4 Bronchiolitis obliterans 
cerebrospinal fluid. ${ }^{416}$ In chronic granulocytic leukaemia bone marrow transplantation is undertaken in the early stable phase when little cytotoxic treatment has been used. ${ }^{317}$ Immediately before transplantation the patient is conditioned with high doses of cytotoxic treatment, which in aplastic anaemia may include horse or rabbit antihuman antithymocyte immunoglobulin, to which is added in most cases of haematological malignancy total body irradiation. With adequate preparation, graft rejection and continuing marrow failure are not seen. After two to three weeks of peripheral blood pancytopenia marrow engraftment ensues. Respectable peripheral blood counts become self sustaining after about one month. Restoration of full immunocompetence may take several years, $T$ cells remaining phenotypically and functionally immature, immunoglobulin concentrations low, and antibody levels reduced. ${ }^{1819}$ The major threat of infection, however-from various bacterial, fungal, viral, and protozoal organisms $\mathrm{s}^{20}$ - comes within the first six months. Prophylaxis against graft versus host disease with methotrexate administration was pioneered in Seattle, ${ }^{22}$ although in recent years many centres have used cyclosporin. ${ }^{23}$ Recently encouraging results have been claimed for $\mathrm{T}$ cell depletion of donor marrow. ${ }^{24}$

\section{Pretransplantation pulmonary function}

In any attempt to assess the importance of pulmonary complications after bone marrow transplantation it is important to recognise that despite the absence of clinical disease patients with leukaemias and aplastic anaemia often have abnormal pulmonary function before transplantation. ${ }^{25}$ In addition, the very different diseases treated with bone marrow transplantation have widely different clinical courses before bone marrow transplantation. For example, a patient with acute myeloid leukaemia may have had a very large number of episodes of both septicaemia and pneumonia before bone marrow transplantation. In contrast, a patient who has a marrow transplantation because of chronic granulocytic leukaemia may never have had an infection. The extent and nature of antibiotic treatment before transplantation varies widely between different disorders and between individuals. Blood component treatment may or may not have been substantial and in some diseases cytotoxic chemotherapy needs to be considered as a possible cause of lung disorder in its own right. Busulphan is used extensively in the treatment of chronic granulocytic leukaemia and was first reported to cause pulmonary fibrosis in $1961 .^{26}$ Acute myeloid leukaemia is treated with anthracyclines (daunorubicin and adriamycin), which are associated with cardiac rather than pulmonary toxicity; and the antimetabolities cytosine arabinoside and thioguanine are infrequently $:$. implicated as pulmonary toxins. ${ }^{27}$ Acute lympho- $\overrightarrow{\vec{F}}$ blastic leukaemia is treated with vincristine and pre $-\frac{7}{0}$ dnisolone, which cause little lung damage by them- $\frac{}{\circ}$ selves; but to these drugs are added the pulmonary toxic antimetabolities mercaptopurine and meth- $\widehat{\Phi}$

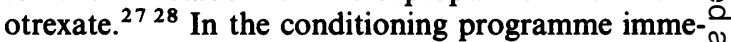
diately before bone marrow transplantation large ${ }^{\infty}$ doses of the alkylating agents cyclophosphamide or $\vec{O}$ melphalan are used. Such drugs in small, long term $\overrightarrow{-}$ doses have been associated with substantial sub- $\omega$ clinical lung damage, but the effects of acute dosing remain to be determined. ${ }^{27}$ Cytotoxic agents damage ${ }^{x}$

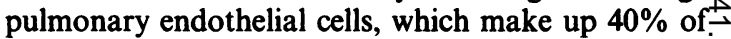
the lung cells and have a turnover rate of $1 \%$ a day in. the steady state, with a potential for accelerated growth when damaged. ${ }^{29}$ It is thus imperative, when ${ }_{0}$ the occurrence of pulmonary toxicity after bone marrow transplantation is being assessed, that previous ${ }_{C}$ cytotoxic treatment and radiation are taken into account.

Total body irradiation with doses of the order of 1000 Gy ( 1000 rads) is used to condition patients for bone marrow transplantation. In animal studies radiationo of this order is associated with increased vascular per-s meability, alveolar wall oedema, and alveolar proteinō leak, with gross loss of lung surfactant. Seven to $28 \%$ days after irradiation alveolar macrophages become 0 reduced in number, pneumocytes degenerate, and $\vec{\sigma}$ hyaline membranes form. Several months later cellu- 3 lar hyperplasia and fibrosis develop. ${ }^{30}$ Attempts to? minimise radiation damage have centred on fractionating the treatment and using low dose rates. High dose pulmonary irradiation results in considerablyo reduced diffusing capacity for the first three months followed by possible minor improvements over a cou-o ple of years. ${ }^{111525}$ When cytotoxic chemotherapy? has not been used, as with some solid tumours, radi-O응 ation to the lungs is rarely associated with appreciable changes in lung volume, forced vital capacity (FVC), 으 forced expiratory volume in one minute $\left(\mathrm{FEV}_{1}\right)$ on the $\mathrm{FEV}_{1} / \mathrm{VC}$ ratio. ${ }^{31}$ But in the long term survivors of bone marrow transplantation who have been conditioned with high dose chemotherapy and irra-? diation restrictive and obstructive lung disease is being described (see below).

In studying the effect upon pulmonary morbidity of allotransplantation between histocompatible siblingso and even unrelated donors it will be important to take्ट into account the experience being gained by using? conditioning regimens in which irradiation is replacedo by additional chemotherapy.

\section{Complications after transplantation}

Perhaps the earliest pulmonary complication of bone marrow transplantation is the rapid onset of pul 
monary oedema associated with volume overload and cardiac dysfunction attributable to previous anthracycline and cyclophosphamide treatment and irradiation. These causes must be distinguished from acute haemorrhagic pulmonary oedema associated with reduced central venous pressure, fluid retention, hypoalbuminaemia, hypotension, and incipient renal failure. ${ }^{1432}$ Histologically, intra-alveolar and occasionally interstitial oedema fluid is seen with red cells and fibrin exudation, but no pneumocyte abnormalities are recognisable. This complication has a high mortality rate and occurs characteristically in patients receiving mismatched transplants and high doses of cyclosporin. The adult respiratory distress syndrome has also been described in allogeneic matched sibling transplants for chronic granulocytic leukaemia. ${ }^{33}$ What causes the pulmonary endothelial damage in these severely neutropenic patients remains unclear as, in this context, neutrophil derived oxidant products seem unlikely to play a part in adult respiratory distress syndrome.

Any patient with pancytopenia and immunosuppression is susceptible to infection ${ }^{34}$ and almost all of these patients have indwelling central venous catheters and many receive parenteral nutrition. Bronchopneumonia associated with few radiological signs when neutrophil counts are low is generally bacterial in origin ${ }^{35}$ and Gram positive organisms often sensitive only to vancomycin are surprisingly common. Pneumonias developing in the neutropenic patient receiving broad spectrum antibiotics may be due to fungi, among which Candida albicans, Aspergillus fumigatus, and the fungi causing mucormycosis are the most common. Recently lobar pulmonary aspergillosis has been linked with sinusitis. ${ }^{36}$

\section{INTERSTITIAL PNEUMONITIS}

Dyspnoea, non-productive cough, fever, widespread crackles, bilateral fluffy infiltrates on the chest radiograph, and hypoxia suggest interstitial pneumonitis. ${ }^{9-13}$ Diagnosis has been improved by cytological, bacteriological, and virological examination of bronchial lavage fluid ${ }^{37}$ to exclude an infectious cause, which is demonstrable in half of all cases. Pathologically, interstitial pneumonitis has been divided into three types depending on the presence of cytomegalovirus inclusion bodies and type II pneumocyte atypia and hyperplasia. ${ }^{14}$

Cytomegalovirus is the major concern. It accounts for most cases of infective interstitial pneumonitis after bone marrow transplantation and characteristically presents six weeks after grafting. It has an alarmingly high mortality rate of about $90 \% .{ }^{910} \mathrm{We}$ must hope that with improvements in early diagnosis afforded by detection of the expression of early cytomegalo virus antigens ${ }^{38}$ and the development of inno- vative antiviral agents ${ }^{39}$ improvements in outlook will occur. The major source of infection is almost certainly reactivation of latent cytomegalovirus in the profoundly immunosuppressed recipient of a bone marrow graft but the contribution of exogenous infection from donor marrow and blood products should not be overlooked. ${ }^{40}$ Ideally the recipient negative for cytomegalovirus antibody should receive marrow and concentrates negative for cytomegalovirus. Even when this is possible cytomegalovirus pneumonitis still occurs, particularly in older patients, who have more severe graft versus host disease and have received more intensive immunosuppressive conditioning regimens before transplantation. ${ }^{9}$ Other viruses, including herpes simplex and varicella viruses and adenovirus, ${ }^{41}$ have been implicated but surprisingly there are few reports documenting infection with influenza and respiratory syncytial virus in recipients of bone marrow grafts. Moreover, the long term effects of these pulmonary infections are unknown.

Unlike interstitial pneumonitis in the acquired immunodeficiency syndrome associated with HTLV III virus, only $4 \%$ of interstitial pneumonitis in immunocompromised recipients of bone marrow grafts is due to Pneumocytis carinii ${ }^{910}$ : the characteristic ground glass appearance on the chest radiograph occurring in the presence of rapidly increasing hypoxia but few auscultatory findings has become rare with the use of prophylactic co-trimoxazole. Recently Legionella pneumophila, ${ }^{42}$ Chlamydia, ${ }^{43}$ and Mycoplasma pneumonias have been reported as causes of interstitial pneumonitis. Because of poor antibody responses in these patients open lung biopsy and sophisticated culture techniques are required for definitive diagnosis, but empirical treatment with erythromycin may be warranted.

The time of onset of an interstitial pneumonitis after bone marrow transplantation has diagnostic importance. In the first two weeks few episodes are found to have an infective cause while most interstitial pneumonitis occurring after 100 days is due to treatable infective causes ${ }^{44}$ : pneumocystis with cotrimoxazole and varicella virus with acyclovir. ${ }^{45}$

Idiopathic interstitial pneumonitis accounts for up to half of all cases reported and is likely to be due to combined drug and radiation toxicity. ${ }^{9-15}$ The International Bone Marrow Transplant Registry reports idiopathic interstitial pneumonitis to be more frequent in older patients, who have a long interval between primary diagnosis and transplantation, and who are then treated with cyclosporin and develop graft versus host disease. Low performance status before transplantation is also a risk factor. ${ }^{9}$ In the Seattle patients radiotherapy seems to be implicated, a lower incidence of pneumonitis being seen when up 
to eight equal fractions, to a total of 12-15 Gy (1200-1500 rads) overall are delivered as opposed to a single dose of $10 \mathrm{~Gy}$. In the larger registry series such discriminants were not evident, but high radiation dose rates in patients receiving methotrexate seem to be harmful. ${ }^{9}$

\section{PULMONARY EMBOLISM}

During marrow harvest fat and bone fragments will inevitably be collected and subsequently infused. Transient hypoxia may occur but no long term parenchymal damage seems to ensue. ${ }^{4647}$ Nevertheless abnormalities of pulmonary vasculature are being recognised with endothelial changes and intimal thickening predisposing to thrombosis of the arterioles, capillaries, and venules that presumably reflects radiation damage. ${ }^{14}$ Pulmonary venoocclusive disease may masquerade as interstitial pneumonitis ${ }^{\mathbf{4 8}}$ and, intriguingly, fat embolisation has been seen as a late complication of bone marrow transplantation. ${ }^{49}$

RESTRICTIVE AND OBSTRUCTIVE LUNG DISEASE Among the later complications of bone marrow transplantation restrictive and obstructive defects of ventilatory function have been reported in subjects who have had pretransplantation conditioning with high dose chemotherapy and irradiation. In over 300 patients with marrow transplants studied in Seattle a mean loss of 0.81 litres of total lung capacity, 0.541 of vital capacity, and $4.4 \mathrm{ml} / \mathrm{min} / \mathrm{mm} \mathrm{Hg}$ of diffusing capacity $\left(1.5 \mathrm{mmol} \mathrm{min}{ }^{-1} \mathrm{kPa}^{-1}\right.$ of transfer factor) was evident one year after transplantation. ${ }^{15}$ In most patients these changes improved over the next three to four years. Obstructive lung disease seems to become more prominent with the passage of time. Reduction in $\mathrm{FEV}_{1} / \mathrm{VC}$ to less than $50 \%, 60 \%$, and $70 \%$ predicted was seen in $0 \%, 2 \%$, and $11 \%$ at three months but in $8 \%, 18 \%$, and $29 \%$ by three years. Unfortunately the pathological findings in patients reported in this study are unknown. What is causing such lung damage remains something of an enigma, since severe obstruction was not attributable in this series to previous whole body irradiation, interstitial pneumonitis, or chronic graft versus host disease.

GRAFT VERSUS HOST DISEASE AND

BRONCHIOLITIS OBLITERANS

The relationship between graft versus host disease and the lung remains uncertain. Although several pulmonary entities have been linked with graft versus host disease, definite evidence that these are true manifestations of graft versus host disease is lacking. Lymphocytic bronchitis with the histological demonstration of lymphocytic infiltration of the bronchial mucosa, loss of cilia and goblet cells, and even necro- sis of mucosa and submucosa has been described as a postmortem finding in $25 \%$ of patients dying after bone marrow transplantation, ${ }^{50}$ many patients having had cough and dyspnoea. Recent studies suggest that these findings relate poorly if at all to the presence of graft versus host disease and are probably due to earlier chemotherapy. ${ }^{51}$ Lymphocytic interstitial pneumonitis has also been reported as a late complication of bone marrow transplantation, ${ }^{52}$ but the relationship of such an entity to graft versus host disease is uncertain and further studies of the lungs of patients with no other evidence of graft versus host disease are needed. In 1982 the first cases of severe irreversible airways obstruction occurring within five months of bone marrow transplantation and in the context of chronic graft versus host disease were reported. ${ }^{53}$ The chest radiograph may be normal, but hyperinflation flat diaphragms and pneumothoraces have been reported, in association with reduced elastic recoil pressure. Histological appearances are those of bronchiolitis obliterans. The clinical course is variable. Treatment with corticosteroids and azathioprine may be of benefit, although the mortality rate remains high. ${ }^{53-58}$ Workers in one centre contend that as many as $13 \%$ of all recipients of marrow grafts have this complication. ${ }^{54}$ Its aetiology may be multifactorial, and it may not necessarily be directly attributable to graft versus host disease itself but may result from recurrent infection or recurrent gastrooesophageal regurgitation. Others contend that it is related to the fibrotic chronic mucositis of the mouth and oesophagus seen in many cases of chronic graft versus host disease.

The contributions, if any, of graft versus host disease and its prophylaxis to pulmonary sequelae after BMT may become clearer by studying the patient who has received an autotransplant. Here marrow is harvested from the patient himself, preserved, and reinfused after intensive chemotherapy or radiation therapy (or both) has been used to control resistant disease. The patient is rescued from bone marrow failure by his own marrow. Such treatment is of potential use in the treatment of solid tumours and is being explored in haematological malignancies, particularly where resistant disease is present in sanctuary sites.

The seriousness of pulmonary damage to patients who have bone marrow transplantation must not be underestimated. Many further studies are needed. Sufficient numbers of patients with similar underlying disorders must be studied. Investigations must detail pretransplant pulmonary function, previous infections, chemotherapy, radiotherapy, transfusions, and smoking history. Sequential assessment of pulmonary function must be performed in relation to clinical events and combined with detailed bacteriological and virological monitoring. Episodes of graft versus 
host disease need to be defined in terms of biopsy changes in relevant tissues. Many more reports of lung biopsy material studied by histological and immunohistochemical means are needed in conjunction with evidence of intensive search for infective organisms, particularly viruses. In this way the causes of pulmonary morbidity may be determined more precisely and the way prepared for prevention and the realisation of the wider application of bone marrow transplantation.

\section{PJ HAMILTON \\ Department of Haematology Royal Victoria Infirmary and University of Newcastle upon Tyne \\ ADJ PEARSON \\ Department of Child Health University of Newcastle upon Tyne}

\section{References}

1 Barranger JA. Marrow transplantation in genetic disease. $N$ Engl J Med 1984;311:1629-31.

2 O'Reilly RJ. Allogenic bone marrow transplantation: current status and future directions. Blood 1983;62: 941-64.

3 Goldman JM, Applerley JF, Jones L, et al. Bone marrow transplantation for patients with chronic myeloid leukaemia. N Engl J Med 1986;314:202-7.

4 Gale RP, Kersey JH, Bortin MM, et al. Bone marrow transplantation for acute lymphoblastic leukaemia. Lancet 1983;ii:663-7.

5 Slavin RE, Santos GW. The graft versus host reaction in man after bone marrow transplantation: pathology, pathogenesis, clinical features and implications. Clin Immunol Immunopathol 1973;1:472-98.

6 Snover DC. Acute and chronic graft versus host disease: histopathological evidence for two distinct pathogenetic mechanisms. Hum Pathol 1984;15:202-5.

7 Shulman HM, Sullivan KM, Weiden PL, et al. Chronic graft versus host disease in man. A long term clinicopathological study of 20 Seattle patients. Am J Med 1980;69:204-17.

8 Sullivan KM, Storb R, Witherspoon RP, et al. Biology and treatment of chronic graft versus host disease. In: Gale RP, ed. Recent advances in bone marrow transplantation. New York: Alan R Liss, 1983:331-42.

9 Weiner RS, Bortin MM, Gale RP, et al. Interstitial pneumonitis following bone marrow transplantation: assessment of risk factors. Ann Intern Med 1986;104:168-75.

10 Myers JD, Flournoy N, Thomas ED. Non-bacterial pneumonia after allogenic bone marrow transplantation: a review of ten years' experience. Rev Infect Dis 1982;4:1119-32.

11 Barrett A, Depledge MH, Powles RL. Interstitial pneumonitis following bone marrow transplantation after low dose rate total body irradiation. Int J Radiat Oncol Biol Phys 1983;9:1029-33.

12 Meyers JD, Flournoy N, Wade JC, et al. Biology of interstitial pneumonia after marrow transplantation. In: Gale RP, ed. Recent advances in bone marrow transplantation. New York: Alan R Liss, 1983:405-43.

13 Zwann FE, Lyklema A, Hermans J. Factors associated with the occurrence of interstitial pneumonitis after bone marrow transplantation for the EBMT-leukaemia working party. Exp Haematol 1984;12 (15):15-16.

14 Sloane JP, Depledge MH, Powles RL, et al. Histopathology of the lung after bone marrow transplantation. J Clin Pathol 1983;36:546-54.

15 Springmeyer SC, Flournoy N, Sullivan KM, Storb R, Thomas ED. Pulmonary function changes in long-term survivors of allogenic marrow transplantation. In: Gale $\mathrm{RP}$, ed. Recent advances in bone marrow transplantation. New York: Alan R Liss, 1983:343-53.

16 Dinsmore R, Kilpatrick D, Flomberg N, et al. Allogenic bone marrow transplantation for patients with acute non-lymphocytic leukaemia. Blood 1984;63:649-56.

17 Thomas ED, Clift RA, Fefer A, et al. Marrow transplantation for treatment of chronic granulocytic leukaemia. Ann Intern Med 1986;104:155-63.

18 Rappeport JM, Dunn MJ, Parkman R. Immature T lymphocytes in the peripheral blood of bone marrow transplant recipients. Transplantation 1983;36:674-80.

19 Witherspoon RP, Storb R, Ochs HD, et al. Recovery of antibody production in human allogenic marrow graft recipients: influence of time post-transplantation, the presence or absence of chronic graft versus host disease and antithymocyte globulin treatment. Blood 1981;58: 360-8.

20 Winston DJ, Gale RP, Meyer JD, Young LS. Infectious complications of human bone marrow transplantation. Medicine 1979;58:1-31.

21 Watson JG. Problems of infection after bone marrow transplantation. J Clin Pathol 1983;36:683-92.

22 Thomas ED, Storb R, Clift RA, et al. Bone marrow transplantation. $N$ Engl $J$ Med 1975;292:832-43, 895-902.

23 Hows JM, Palmer S, Gordon-Smith EC. Use of cyclosporin $\mathbf{A}$ in allogenic bone marrow transplantation for severe aplastic anaemia. Transplantation 1982;33: 382-6.

24 Prentice HG, Blacklock HA, Janossy G, et al. Depletion of $\mathrm{T}$ lymphocytes in donor marrow prevents significant graft-versus-host disease in matched allogenic leukaemia marrow transplant recipients. Lancet 1984;i:472-6.

25 Depledge MH, Barrett A, Powles RL. Lung function after bone marrow grafting. Int J Radiat Oncol Biol Phys 1983;9:145-51.

26 Oliner H, Schwartz R, Rubio F, Damasheck W. Interstitial pulmonary fibrosis following busulfan therapy. Am J Med 1961;31:134-9.

27 Ginsberg SJ, Comis RL. The pulmonary toxicity of antineoplastic agents. Semin Oncol 1982;9:34-51.

28 St Clair EW, Rice JR, Snyderman R. Pneumonitis complicating low dose-methotrexate therapy in rheumatoid arthritis. Ann Intern Med 1985;145:2035-8.

29 Bowden DH. Cell turnover in the lung. Am Rev Respir Dis 1983;126:46-8.

30 Barrett A. Relationship of irradiation to pulmonary complications. Exp Hematol 1984;12(15):6-7.

31 Abbatucci JS, Boulier A, Fabre J, Lozier JC. Functional evaluation of pulmonary bilateral irradiation effects. Eur $J$ Cancer 1975;14:781-5.

32 Depledge MH, Barrett A, Morgenstern G, Sloane JP, Powles RL. Pulmonary oedema with leaky endothelial syndrome. Exp Hematol 1982;10(10):113.

33 Braude S, Apperley J, Krausz T, et al. Adult respiratory distress syndrome after allogenic bone marrow transplantation. Evidence for a neutrophil-independent 
mechanism. Lancet 1985;i:1239-42.

34 Bodey GP, Rodriguez V, Chang H-Y, Narboni G. Fever and infection in leukaemic patients. Cancer 1978;41: 1610-22.

35 Commers JR, Robichaud KJ, Pizzo PA. New pulmonary infiltrates in granulocytopenic cancer patients being treated with antibiotics. Ped Infect Dis 1984;3:423-8.

36 Berlinger NT. Sinusitis in immunodeficient and immunosupressed patients. Laryngoscope 1985;95:29-33.

37 Hopkin JM, Young JA, Turney JH, Adu D, Michael J. Rapid diagnosis of obscure pneumonia in immunosuppressed renal patients by cytology of the alveolar lavage fluid. Lancet 1983;ii:299-301.

38 Griffiths PD, Panjwani DD, Stirk RR, et al. Rapid diagnosis of cytomegalovirus infection in immunocompromised patients by detection of early antigen fluorescent foci. Lancet 1984;ii:1242-5.

39 Klintmalm G, Lonnqvist B, Oberg BO, et al. Intravenous foscarnet for the treatment of severe cytomegalovirus infection in allograft recipients. Scand $J$ Infect Dis 1985;17:157-63.

40 Meyers JD, Flournoy N, Thomas ED. Cytomegalovirus infection and specific cell mediated immunity after marrow transplant. $J$ Infect Dis 1980;142:816-24.

41 Shields AF, Hackman RC, Fife KH, Corey L, Meyers JD. Adenovirus infections in patients undergoing bone marrow transplantation. $N$ Engl J Med 1985;312:529-33.

42 Kugler JW, Armitage JO, Helms CM, et al. Nosocomial legionnaires' disease: occurrence in recipients of bone marrow transplants. Am J Med 1983;74:281-8.

43 Meyers JD, Hackman RC, Stamm WE. Chlamydia trachomatis infection as a cause of pneumonia after human marrow transplantation. Transplantation 1983;36:130-4.

44 Wingard JR, Santos GW, Saral R. Late-onset interstitial pneumonia following allogenic bone marrow transplantation. Transplantation 1985;39:21-3.

45 Shepp DH, Dandliker PS, Meyers JD. Treatment of varicella-zoster virus infection in severely immunocompromised patients. A randomized comparison of acyclovir and vidarabine. $N$ Engl J Med 1986;314: 208-12.

46 Springmeyer SC, Silvestri RC, Flournoy N, et al. Pulmonary function of marrow transplant patients: I Effects of marrow infusion, acute graft-versus-host disease and interstitial pneumonitis. Exp Haematol 1984;12:805-10.

47 Abrahams C, Catchatourian R. Bone fragment emboli in the lungs of patients undergoing bone marrow transplantation. Am J Clin Pathol 1983;79:360-3.

48 Troussard X, Bernaudin JF, Cordonnier C, et al. Pulmonary veno-occlusive disease after bone marrow $\frac{\bar{\rho}}{\bar{D}}$ transplantation. Thorax 1984;39:956-7.

49 Paradinas FJ, Sloane JP, Depledge MH, et al. Pulmonary fat embolisation after bone marrow trans- $\omega$ plantation. Lancet 1983;1:715-6.

50 Beschorner WE, Saral R, Hutchins GM, Tutschka PJ, Santos GW. Lymphocytic bronchitis associated with $\vec{\omega}$ graft-versus-host disease in recipients of bone marrow $\omega$ transplants. $N$ Engl J Med 1978;299:1030-6.

51 O'Brien KD, Hackman RC, Sale GE, et al. Lymphocytic bronchitis unrelated to acute graft versus host disease $₫$ in canine marrow graft recipients. Transplantation $-\mathrm{V}$ 1984;37:233-8.

52 Perreault C, Cousineau S, D’Angio G, et al. Lymphoid interstitial pneumonia after allogenic bone marrow 음 transplantation. Cancer 1985;55:1-9.

53 Roca J, Granena A, Rodriguez Roisin R, Alvarez P, $\vec{c}$ Agusti-Vidal A, Rozman C. Fatal airways disease in an adult with chronic graft versus host disease. Thorax 1982;37:77-8.

54 Wyatt SE, Nunn P, Hows JM, et al. Airways obstruction associated with graft versus host disease after bone marrow transplantation. Thorax 1984;39:887-94.

55 Johnson FL, Stokes DC, Ruggiero M, Dallapozza L, \} Callihan TR. Chronic obstructive airways disease after bone marrow transplantation. J Pediat 1984;105:370-6.

56 Ralph DD, Springmeyer SC, Sullivan KM, et al. Rapidly progressive air-flow obstruction in marrow transplant $\varrho$ recipients-possible association between obliterative $\overrightarrow{\vec{B}}$ bronchiolitis and chronic graft versus host disease. Am Rev Respir Dis 1984;129:641-3.

57 Link H, Reinhard D, Neithammer D. Obstructive ventilation disorders as a severe complication of chronic graft versus host disease after bone marrow transplantation. Exp Haematol 1982;10:92-3.

58 Ostrow D, Buskard N, Hill RS, Vickars L, Churg A. \} Bronchiolitis obliterans complicating bone marrow $\bar{\sigma}$ transplantation. Chest 1985;87:828-30. 